\title{
ANALYSIS OF THE EVOLUTION OF SMES IN WESTERN ROMANIA BETWEEN 2011-2014, USING THE MATHEMATICAL MODELLING
}

\author{
Loghin Gaga \\ Department of Mathematics, \\ West University of Timisoara, Timisoara, Romania \\ gagaloghin@yahoo.com \\ Andrei Gabor \\ agabor2002@yahoo.com \\ Antonela Naaji \\ anaaji@uvvg.ro \\ Marius Constantin Popescu \\ mpopescu@uvvg.ro \\ Department of Engineering and Computer Science, \\ Vasile Goldis Western University, Arad, Romania
}

(Received July 2016; Accepted October 2016)

\begin{abstract}
The SMEs in Romania, which remained reliable after the economic crisis, had a better dynamic of business development in relation to large and very large companies. The increase of the fiscal value of these companies has improved every year, leading to spectacular results in certain fields of activity, particularly services, trade and IT. After the economic crisis, the SMEs from the Western region had a dynamic business market, outstripping all other regions of economic development. The result was the increase in the number of SMEs and the number of jobs in this region. In this article, we propose a mathematical model based on multivariate analysis, specifically on cluster analysis, in order to analyse the economic activities of SMEs in the Western development region. Cluster analysis is a multivariate analysis method that includes algorithms able to identify and group efficiently and descriptively a similar group in terms of certain common properties, in a lot of time objects.

The purpose of this paper is the analysis of the economic efficiency of SMEs' activities in the Western area of Romania and the extraction of activities through modeling in order to maximise the efficiency of the companies in the future.
\end{abstract}

Key words: SME development, efficiency, multivariate analysis, cluster analysis

J.E.L. CODES: A12, C10, C65, D80, M21

\section{Introduction}

The business environment in Romania, adapted more and more to the competitive requirements of the legislation of the European Union (EU), has evolved in the last 25 years, from $98 \%$ large and very large enterprises in 1990 to $99 \%$ micro small

94 Studia Universitatis "Vasile Goldis" Arad. Economics Series Vol 26 Issue 4/2016 ISSN: 1584-2339; (online) ISSN: $2285-3065$

Web: publicatii.uvvg.ro/index.php/studiaeconomia.Pages $94-107$ 
and medium enterprises (SMEs) in 2014. Horizontal economic relations between small and medium enterprises and vertically between SMEs and large enterprises have generated a dynamic and competitive business environment, which has resulted in the steady growth of the number of SMEs, increasing fiscal value and economic efficiency (CNIPMMR, 2011).

There are numerous studies showing that increasing the efficiency of large and very large companies is based on modern knowledge management systems, on innovation and intensive collaboration with SMEs. Studies in recent years, Gordon and McCann, (2005), Gunasekaran and Ngai, (2007), Andreas Heck et al, (2012), Anyadike-Danes et al., (2015), Ciucan-Rusu et al. (2013), show that SMEs have a crucial role, both in developing the economic efficiency of large and very large enterprises and in economic development in the world, EU and Romania. Research concerning the efficiency of SMEs, by applying new technology, knowledge and innovation, Ciucan-Rusu et al. (2013), Lukacs, E (2005), Bonifacio Garcia Porras (2014), Patrice Muller at al. (2015), Man, M., and Macris, M. (2013), Bianchi, M. at al. shows that knowledge management is almost unused in European SMEs, Romanian SMEs and beyond and where it is applied, it is sporadic and inhomogeneous (Neagu, 2016), (Mot 2014).

According to the National Statistics Institute (NSI), in 2014, the SME sector in Romania, in general, and in the Western development area, in particular, was dominated by very small enterprises (less than 9 employees) and small ones, so by very small and small companies in more than $99 \%$. The financial and economic efficiency of very small companies is usually low because of the reduced development prospects, due to the following factors: fewer opportunities to access funds to enable them to develop (Patrice Muller at al., 2015), the lack of strategies for effective management of knowledge, little interest for innovation and development of marketing strategies for market expansion of the products they manufacture or sell, little interest for continuous training of staff and directors, lack of interest or fear of financial reimbursable loans (Bianchi,M at al., 2010).

Western region, mainly Timis and Arad counties, faces a faster social-economic efficiency of SMEs due to investment of German and Austrian companies, leading to fall of unemployment and increased profit. The main problems that the SMEs from the western part of Romania have to face, in addition to the national situation, based on the survey results, are: low demand, the quality of SMEs commercial offer, lack of funding (or funding cumbersome, high costs of financing activity), high taxation, lack of economic efficiency (due to micro size of the majority of SMEs in the region), the debts accumulated during the crisis, etc. (Popa, L., 2013). 
Gaga L., Gabor A., Naaji A., Popescu M.P. (2016)

Analysis of the evolution of SMEs in Western Romania between 2011-2014, using the mathematical modeling

A future studies of economic and financial efficiency of SMEs in the Western development area will contribute to finding measures for streamlining the activities which best fit the area's development. The objectives of our study are:

- Clustering, through mathematical methods, of the relevant activities from both financial and economic point of view, for each county in the Western part of Romania;

- The analysis of the relevant groups that have resulted from using the cluster analysis;

- Remodelling of both the financial and economic strategies to emphasise the economic activities, without going bankrupt.

\section{The analysis of SMEs in the EU, Romania and Western development region after the economic crisis (2008-2010)}

SMEs are made up of micro, small and medium enterprises with different characteristics (Table 1).

Table 1. SMEs' Characteristics

\begin{tabular}{|l|c|l|}
\hline \multicolumn{1}{|c|}{ Company type } & Number of staff & \multicolumn{1}{c|}{ Fiscal value } \\
\hline micro enterprise & $0-9$ & $\leq 2$ million $€$ \\
\hline small business & $10-49$ & $\leq 10$ million $€$ \\
\hline medium enterprise & $50-249$ & $\leq 50$ million $€$ \\
\hline
\end{tabular}

Source: own calculations based on http://www.aippimm.ro/articol/imm/legislatie$\mathrm{imm} /$ definitie-imm

Currently, it is estimated that the SME sector in the EU has the fastest growth and it represents the basis of national economy of the component countries. The entire SME sector is considered to be the engine of national economies and it is the subject of numerous specialized studies, Isarescu, M. (2011), Katz, J., Green, R. (2009), Popa, L. (2013), Bostan, I. (2014). The approaches to evolution and expansion of the SME became important for the study and research of the effects upon the development perspective, efficient use of resources, especially local ones, the continuous attraction and specialization of labour, especially the young branch, etc. [30]. From the data published by Eurostat [Eurostat regional yearbook 20112015] one can deduce that in 2015, 99.7\% of the EU enterprises are SMEs and $99 \%$ of these are represented by micro-enterprises [28].

In addition, about $70 \%$ of the employed population works in SMEs. The number of SMEs in the EU in 2015 was approximately 22 million, compared to 2008 -the year when the economic crisis in the EU began. There were 
approximately 21.500.000 SMEs companies (Eurostat Statistical Atlas 20112015). The increase in the number of SMEs in 2015, reported to the beginning of the economic crisis, is $2.33 \%$ [29].

However, the largest increase in the number of SMEs in Europe occurred in 2011, which represented a year of economic "boom" after the crisis of industrialized countries in the EU. Thus, in 2011 the number of SMEs in the EU was about 22.128 million [Eurostat Statistical Atlas 2011-2015], representing an increase of $2.92 \%$ compared to 2008. It shows a decrease of $0.59 \%$ in the number of SMEs in EU in 2014 compared to 2011. In terms of working population in the SMEs in EU, it represents in 2015, approximately 91 million, while in 2008, the year of the economic crisis, there were about 92 million employees in SMEs, representing a decrease of $1.09 \%$ of the population engaged in SMEs firms. Analysing the facts, there is a continuous decline in employment in European SMEs by 2013, followed by continuous increases in 2014 with the clear upward trend in 2015. Examining the growth trend for 2015 in comparison with 2013 there is an apparent increase of $0.85 \%$.

In Romania the importance of SMEs for job creation and rapid development sector is essential. SMEs in Romania now represent $98.6 \%$ of existing businesses in the country, which means that at the end of 2014 there were 492.000 companies. About $85 \%$ of the activity of Romanian SMEs focuses on the following sectors: trade, IT services, professional activities, technical and scientific construction industry. In Romania, SMEs absorbed in 2014, $70 \%$ of the working population (according to the White Chart of SMEs in Romania, 2015). The number of micro companies, below 9 workers, remains unchanged in the studied period. Annually, the number of new SMEs increases in absolute size. Researching the increasing number of SMEs created between 2011- 2014, we can see that, compared to 2008, the percentage increased by $33.2 \%$, at the end of 2014 .

Regarding the number of SMEs by type of activities, from the statistical data, we can notice a slight constant growth in all sectors surveyed. Based on NSI data, the changes in the number of SMEs in Romania, between 2011 and 2014, are shown in Table 2. Based on data from the White Chart of SMEs in Romania in 2011-2015, there is a growth in income for micro enterprises, which quickly recovers the loss during the crisis.

The fiscal value of SMEs in Romania has a constant positive trend during the studied period, the highest growth rates being in trade, manufacturing, IT as evidenced by the National Statistics Institute (NSI) report for 2016. The fiscal value of fast growing companies and gazelle companies is significant in the studied period, but their number decreases over this period, from approximately $2 \%$ of the total number of companies to approximately $1 \%$.On the whole, we conclude that 
Gaga L., Gabor A., Naaji A., Popescu M.P. (2016)

Analysis of the evolution of SMEs in Western Romania between 2011-2014, using the mathematical modeling

SMEs in Romania had a positive development between 2011 and 2014, with a relatively spectacular comeback in 2015 .

Table 2. Comparison between the numbers of SMEs in the West region, by sectors of activity

\begin{tabular}{|l|r|r|r|}
\hline \multicolumn{1}{|c|}{ Sector } & \multicolumn{1}{c|}{$\mathbf{2 0 1 1}$} & \multicolumn{1}{c|}{$\mathbf{2 0 1 4}$} & $\mathbf{2 0 1 4 / 2 0 1 1}$ \\
\hline Trade activities & 213105 & 214568 & $100.69 \%$ \\
\hline IT and professional activities & 68875 & 78653 & $114.20 \%$ \\
\hline Construction & 64212 & 62955 & $98.04 \%$ \\
\hline Transport and storage & 43945 & 55678 & $126.70 \%$ \\
\hline Industry & 55432 & 56733 & $102.35 \%$ \\
\hline Services & 38673 & 42800 & $110.67 \%$ \\
\hline
\end{tabular}

Although during the economic crisis of the years 2008-2010, the situation of SMEs in the Western area was poor - their number as well as their fiscal value dropped significantly in comparison with 2007. Since 2011 there has been a revival of SME sector development in this area.

This conclusion results from dynamic employment growth in this area of development, being the best one in the country. After processing the data from SME Charter 2015 it is obvious that between 2011 and 2014 the number of jobs in the Western region increased by about 31.450. Evolution of jobs in 2014 compared to 2011 is $22.6 \%$. Also, by processing NSI data, due to increasing competition in the labour market, but also in the competence of employees, we notice that the average wages in SMEs in the Western Region is over 2000 lei in 2014.

The reasons of the rapid development of SMEs in the Western development area are:

- growth in demand, due to fiscal easing;

- extension of the minimum wages and all income of household consumption, after 2011 ;

- the establishment of foreign companies, mainly in the automotive industry, subsidiaries of SMEs in the West, very profitable in terms of attracting employment and retraining of the jobs required;

- cheap labour, especially in rural areas - lacking a stable income - easily retrained. The research on the evolution and effectiveness of SMEs development in the West are scarce or non-existent. Therefore, in this paper, an analysis is made based on statistical data and considering a representative sample of 4 counties from Western development region. This analysis shows the situation of SMEs in 2011-2014, with reference to the 2015. Its purpose is to determine the types of activities and 
enterprises in the Western region in order to increase the sense of economic and financial efficiencies with a stable trend. The research method employed is one of multivariate mathematical modeling, namely Cluster method.

\section{Methodology}

Data analysis aims at extracting information contained in the data. This information is used to interpret various phenomena in the economy, technology, finance, etc.; to estimate or predict the evolution of phenomena. To be analyzed, the data is organized as a matrix, where the columns are represented by variables and the lines by observations.

Cluster method is a method of multivariate analysis that identifies homogeneous data groups and consists of a collection of techniques by which a set of objects is divided into relatively homogeneous groups. The essential objective of cluster analysis is to classify the objects into groups of the same type that have similar properties to each other according to a given set of variables. Research concerning the application of multivariate analysis is the subject for many studies, Voineagu et al., (2002), Babucea, A.G. (2003), Danacica, D.E. (2006) et al. In cluster analysis, neither the number, nor the group members are known. The study starts with no knowledge of the group structure and it is not known how many clusters there are. Cluster represents many elements alike, elements that cannot be found in another cluster. Cluster method applies algorithms that categorize items, objects in homogeneous groups whose analysis involves determining the similarity, proximity, using mathematical methods. Thus, it determines the starting points from which the hierarchical clustering (cluster center) starts, it analyses information on the elements combined in hierarchical groups (agglomeration schedule); it calculates the sum of values for the elements of the cluster (cluster centroid); it determines the membership to the group for the objects that are researched.

Clustering techniques based on algorithms ascendants (elements are built by associating similar classes and a hierarchy is obtained) and descendants algorithms (algorithm to divide into homogeneous subsets of elements), which is hierarchical analysis (Hierarchical cluster analysis) (Blei, D.M, 2008). Another type of algorithms applied in clustering techniques is the partitioning algorithms (starting with a partition of crowd elements and hierarchical classes are obtained, by the migration of the elements between the obtained classes) (Blei, D.M, 2008), (Armeanu, S.D. et al., 2015).

The data structures that are used in cluster analysis are: the matrix of objects, the matrix of similarity based on the correlation coefficient, matrix of dissociation based on Euclidean distance (31- SPSS for Windows) 
Gaga L., Gabor A., Naaji A., Popescu M.P. (2016)

Analysis of the evolution of SMEs in Western Romania between 2011-2014, using the mathematical modeling

Also, of great importance is the distance between group objects, the distance between groups or classes, because choosing a certain distance may change essentially the groups that are obtained. Based on the definition of the distance, the matrix of similarity was obtained.

As a result of the use of algorithms we get a scheme that differentiates clusters obtained from data classification, called dendrogram, or tree, which shows a summary of the hierarchy of classes.

\section{The Analysis of the Evolution of SMEs in the Western Development Region in 2014, based on the Cluster}

In the analysis of the work, 1654 SMEs were taken into consideration, SMEs that were representative in the Western region and were grouped by activity. 959 SMEs responded to the survey, which represent a very significant percentage for this activity. Percentages of each activity reports were taken into account for all economic activities (100\%) of SMEs in each county.

Table 3. The SMEs share repartition (\%) based on the main activities of the Western counties (according to the economic efficiency)

\begin{tabular}{|l|c|c|c|c|}
\hline Activities & Arad & $\begin{array}{c}\text { Caras- } \\
\text { Severin }\end{array}$ & Hunedoara & Timis \\
\hline Trade & 0.310 & 0.290 & 0.330 & 0.330 \\
\hline Transport and storage & 0.140 & 0.070 & 0.080 & 0.085 \\
\hline Manufacturing industry & 0.220 & 0.240 & 0.250 & 0.210 \\
\hline Construction & 0.070 & 0.080 & 0.100 & 0.100 \\
\hline Information and Communications Technology & 0.050 & 0.040 & 0.025 & 0.070 \\
\hline Administrative and support services & 0.010 & 0.010 & 0.011 & 0.015 \\
\hline Real estate & 0.012 & 0.011 & 0.010 & 0.020 \\
\hline Health and social care & 0.010 & 0.004 & 0.010 & 0.016 \\
\hline Hotels and restaurants & 0.025 & 0.010 & 0.020 & 0.020 \\
\hline Cultural performances and entertainment & 0.020 & 0.020 & 0.020 & 0.010 \\
\hline Education & 0.008 & 0.015 & 0.010 & 0.013 \\
\hline Financial and insurance mediation & 0.012 & 0.020 & 0.012 & 0.013 \\
\hline Waste management & 0.010 & 0.025 & 0.015 & 0.015 \\
\hline Extractive industry & 0.010 & 0.025 & 0.025 & 0.015 \\
\hline Production and supply of electricity and heat & 0.020 & 0.050 & 0.022 & 0.008 \\
\hline Agriculture & 0.073 & 0.090 & 0.060 & 0.060 \\
\hline Total & 1.000 & 1.000 & 1.000 & 1.000 \\
\hline Source: & &
\end{tabular}

Source: own calculations based on statistical research conducted [18], [22], [23], [25] 
Gaga L., Gabor A., Naaji A., Popescu M.P. (2016)

Analysis of the evolution of SMEs in Western Romania between 2011-2014, using the mathematical modeling

Firstly, the group has researched the main activities of SMEs in the Western region based on economic efficiency, according to the data processed and concentrated in Table 3.

After processing the resulted data (Table 3), the SMEs hierarchy was analyzed based on their profile in order to determine the future opportunities regarding the fast growth of the performed activities' efficiency. For data processing it was used a multivariate analysis method, namely Cluster analysis using IBM SPSS Statistics software v.20 and the Pearson coefficient was applied for calculating the distance. The distances for each case, presented in the matrix of proximity Table 4), plotted (Figure1), highlight the cases that have the most common points, or the connections between groups (Table 5). One can notice the grouping method of the cases and the obtained groups, obtaining the values for the coefficients of distances between obtained groups (Table 5) and the dendrogram (Figure 2).

Table 4. The matrix of proximity

\begin{tabular}{|l|r|r|r|r|r|r|r|r|}
\hline \multirow{2}{*}{ Case } & \multicolumn{7}{|c|}{ Correlation between Vectors of Values } \\
\cline { 2 - 10 } & \multicolumn{1}{|c|}{1} & \multicolumn{1}{c|}{2} & \multicolumn{1}{c|}{3} & \multicolumn{1}{c|}{4} & \multicolumn{1}{c|}{5} & \multicolumn{1}{c|}{6} & \multicolumn{1}{c|}{7} & \multicolumn{1}{c|}{8} \\
\hline 1 & 1.000 & 0.014 & -191 & 0.754 & 161 & 0.658 & 438 & \multicolumn{1}{c|}{0.853} \\
\hline 2 & 0.014 & 1.000 & -464 & -645 & 228 & -256 & -043 & 195 \\
\hline 3 & -191 & -464 & 1.000 & 122 & -967 & -614 & -838 & -671 \\
\hline 4 & 0.754 & -645 & 122 & 1.000 & 0.015 & 700 & 401 & 544 \\
\hline 5 & 161 & 228 & -967 & 0.015 & 1.000 & 0.723 & 0.922 & 649 \\
\hline 6 & 0.658 & -256 & -614 & 700 & 0.723 & 1.000 & 0.934 & 0.857 \\
\hline 7 & 438 & -043 & -838 & 401 & 0.922 & 0.934 & 1.000 & 0.803 \\
\hline 8 & 0.853 & 195 & -671 & 544 & 649 & 0.857 & 0.803 & 1.000 \\
\hline 9 & 0.623 & 0.789 & -435 & -044 & 228 & 167 & 188 & 649 \\
\hline 10 & -522 & 185 & 730 & -556 & -839 & -980 & -984 & -816 \\
\hline 11 & -392 & -809 & 0.059 & 250 & 185 & 270 & 270 & -263 \\
\hline 12 & -834 & -545 & 284 & -273 & -120 & -308 & -212 & -740 \\
\hline 13 & -623 & -789 & 435 & 0.044 & -228 & -167 & -188 & -649 \\
\hline 14 & -174 & -857 & 0.852 & 407 & -692 & -233 & -474 & -544 \\
\hline 15 & -881 & -379 & 0.596 & -438 & -512 & -693 & -636 & -965 \\
\hline 16 & -998 & -083 & 218 & -707 & -172 & -635 & -429 & -861 \\
\hline
\end{tabular}

DE GRUYTER OPEN
Studia Universitatis "Vasile Goldis" Arad. Economics Series Vol 26 Issue 4/2016 ISSN: 1584-2339; (online) ISSN: 2285 - 3065 
Gaga L., Gabor A., Naaji A., Popescu M.P. (2016)

Analysis of the evolution of SMEs in Western Romania between 2011-2014, using the mathematical modeling

\begin{tabular}{|l|r|r|r|r|r|r|r|r|}
\hline \multirow{2}{*}{ Case } & \multicolumn{7}{|c|}{ Correlation between Vectors of Values } \\
\cline { 2 - 10 } & \multicolumn{1}{|c|}{9} & \multicolumn{1}{c|}{10} & \multicolumn{1}{c|}{11} & \multicolumn{1}{c|}{12} & \multicolumn{1}{c|}{13} & \multicolumn{1}{c|}{14} & \multicolumn{1}{c|}{15} & \multicolumn{1}{c|}{16} \\
\hline 1 & 0.623 & -522 & -392 & -834 & -623 & -174 & -881 & -998 \\
\hline 2 & 0.789 & 185 & -809 & -545 & -789 & -857 & -379 & -083 \\
\hline 3 & -435 & 730 & 0.059 & 284 & 435 & 0.852 & 0.596 & 218 \\
\hline 4 & -044 & -556 & 250 & -273 & 0.044 & 407 & -438 & -707 \\
\hline 5 & 228 & -839 & 185 & -120 & -228 & -692 & -512 & -172 \\
\hline 6 & 167 & -980 & 270 & -308 & -167 & -233 & -693 & -635 \\
\hline 7 & 188 & -984 & 270 & -212 & -188 & -474 & -636 & -429 \\
\hline 8 & 649 & -816 & -263 & -740 & -649 & -544 & -965 & -861 \\
\hline 9 & 1.000 & -132 & -895 & -943 & 1000 & -751 & -820 & -675 \\
\hline 10 & -132 & 1.000 & -322 & 216 & 0.132 & 0.333 & 0.638 & 504 \\
\hline 11 & -895 & -322 & 1.000 & 0.819 & 0.895 & 536 & 507 & 449 \\
\hline 12 & -943 & 216 & 0.819 & 1.000 & 0.943 & 0.532 & 888 & 0.869 \\
\hline 13 & 1000 & 0.132 & 0.895 & 0.943 & 1.000 & 0.751 & 820 & 675 \\
\hline 14 & -751 & 0.333 & 536 & 0.532 & 0.751 & 1.000 & 0.613 & 230 \\
\hline 15 & -820 & 0.638 & 507 & 888 & 820 & 0.613 & 1.000 & 0.903 \\
\hline 16 & -675 & 504 & 449 & 0.869 & 675 & 230 & 0.903 & 1.000 \\
\hline
\end{tabular}

Source: own calculations based on Table 3

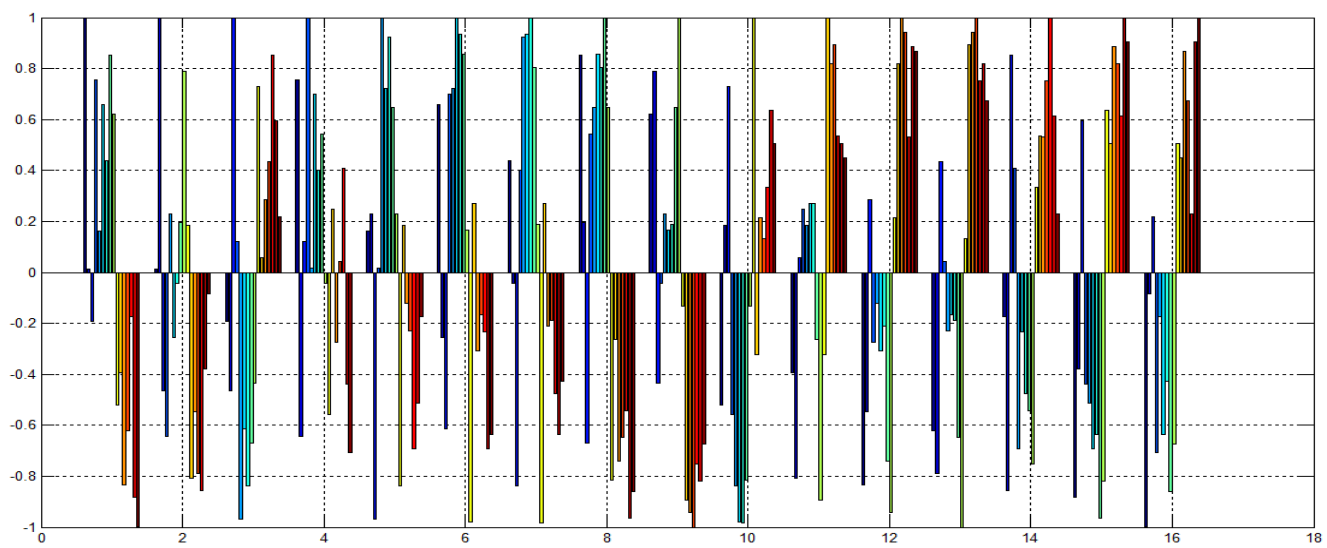

Figure 1 Representation for the matrix of proximity

Source: own calculations based on IBM SPSS and Table 4 
Gaga L., Gabor A., Naaji A., Popescu M.P. (2016)

Analysis of the evolution of SMEs in Western Romania between 2011-2014, using the mathematical modeling

From the matrix of proximity we can deduce that scores above 0.5 , which represent strong associations between economic activities, can be seen between activities 1$6-8 ; 2-9 ; 03 / 10 / 14 ; 4-6$ etc. These associations of activities will lead the SMEs in the area of increased economic efficiency.

Table 5. Average Linkage - between groups

\begin{tabular}{|c|c|c|c|c|c|c|}
\hline & & & & & \multicolumn{2}{|l|}{ retenners- } \\
\hline Stage & $\begin{array}{l}\text { Cluster } \\
\text { Cluster } 1\end{array}$ & Imbined & corricients & $\begin{array}{c}\text { Stage Cluste } \\
\text { Cluster } 1\end{array}$ & $\begin{array}{l}\text { Ist Appears } \\
\text { Cluster? }\end{array}$ & \\
\hline 1 & 12 & 13 & .943 & o & 0 & 4 \\
\hline 2 & 6 & 7 & .934 & 0 & o & 7 \\
\hline 3 & 15 & 16 & .903 & 0 & o & 9 \\
\hline 4 & 11 & 12 & .857 & o & 1 & 9 \\
\hline 5 & 1 & 8 & .853 & 0 & o & 10 \\
\hline 6 & 3 & 14 & .852 & o & o & 11 \\
\hline 7 & 5 & 6 & .823 & 0 & 2 & 12 \\
\hline 8 & 2 & 9 & .789 & o & o & 14 \\
\hline 9 & 11 & 15 & .701 & 4 & 3 & 13 \\
\hline 10 & 1 & 4 & .649 & 5 & 0 & 12 \\
\hline 11 & 3 & 10 & .532 & 6 & o & 13 \\
\hline 12 & 1 & 5 & .520 & 10 & 7 & 14 \\
\hline 13 & 3 & 11 & .361 & 11 & 9 & 15 \\
\hline 14 & 1 & 2 & 109 & 12 & 8 & 15 \\
\hline 15 & 1 & 3 & -.482 & 14 & 13 & o \\
\hline
\end{tabular}

Source: own calculations based on IBM SPSS and Table 4

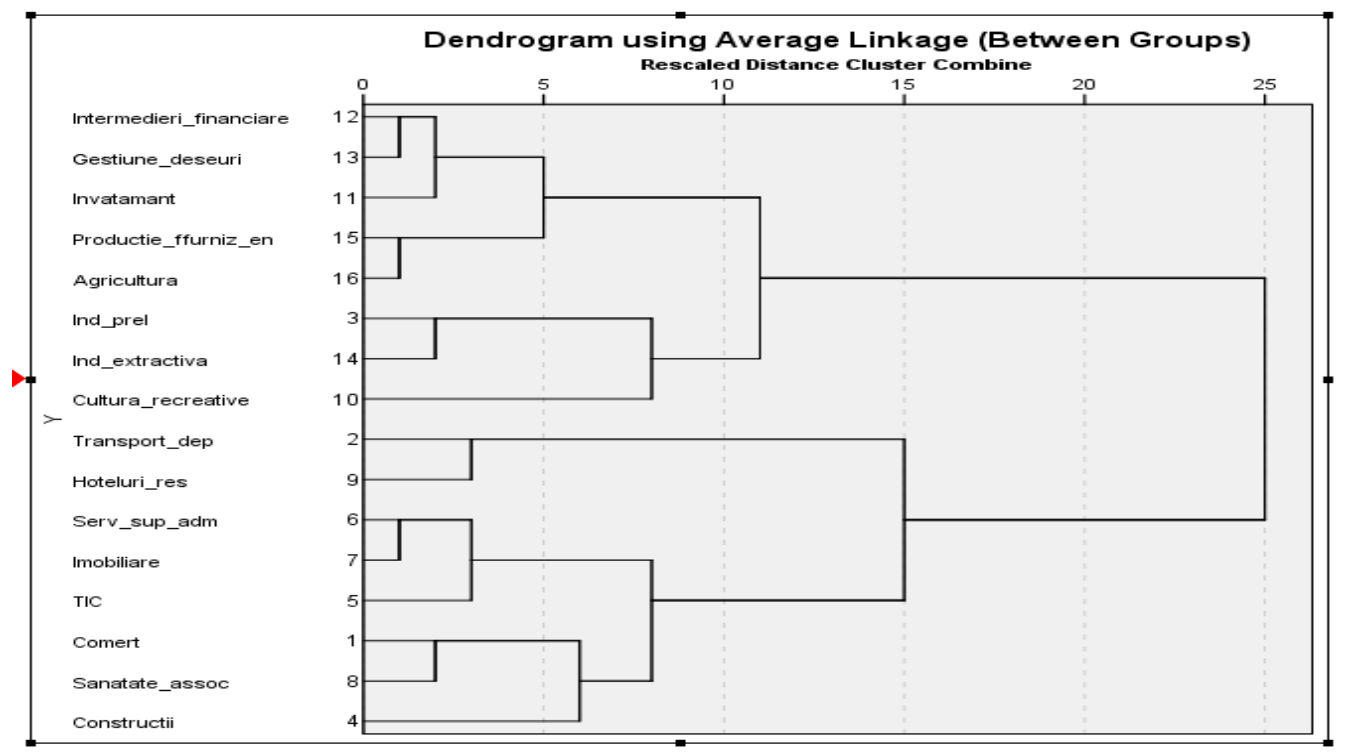

Figure 2 Dendrogram

Source: own calculations based on IBM SPSS and Table 5

Based on the dendrogram it can be noticed that the activities 6, 7 and 13 are grouped together by the slightest difference (approx. 1), therefore, the importance

DE GRUYTER Studia Universitatis "Vasile Goldis" Arad. Economics Series Vol 26 Issue 4/2016 
of these activities is approximately equal in the four counties, from the entrepreneur's interest point of view. Of equal importance, for the entrepreneurs of the two counties, with the coefficient of importance of approx. 2 are the activities $8,11,12$ and 14. Activities 1,4 and 5 have the coefficient of importance of approx. 5. It turns out that the biggest perspective, which will bring the most important benefits to the entrepreneurs in the SME sector, is held by the trade activities, manufacturing, information and communication technology and transport and storage.

\section{Conclusions}

The SMEs in the Western region counties are focusing their economic activity on activities that have a high economic efficiency. From the dendrogram and the matrix of proximity we can notice that the biggest development perspectives are held by the SMEs in the fields of storage, transport, trade, construction, information and communication technology, which are interconnected by various levels to other activities of lesser importance.

Comparing the results obtained using the Pearson coefficient method to those obtained using the Cityblock method, it can be noticed, again, that the activities 6 , $7,8,9,11,12,13$, have a 1 similarity degree, so there is a small percentage of differences for the four counties. The biggest differences regarding the effectiveness of the researched activities are between activities 1 and 3 and among other researched activities.

For counties, from the analysis made by the proximity calculation using the CityBlock method, it turns out that the greatest difference between Timis and Caras-Severin, Arad-Caras-Severin, Timis-Hunedoara, Arad-Hunedoara, Timis and Arad counties regarding the effectiveness of SMEs researched in the Western area is more obvious in this part of the country because these regions are more economically and financially efficient. The lowest proximity coefficient is between Hunedoara and Caras Severin, which shows that these counties have about the same efficiency of SMEs on researched activities, much less than the efficiency of SMEs in Arad and Timis counties.

Based on researched activities we can conclude that among the Western counties, the highest growth perspective of economic efficiency is held by the SMEs in Arad and Timis counties. Hunedoara has a very good and promising trend and in CarasSeverin there are factors that lead to stagnation in the researched SMEs activities. The survey conducted by us, through mathematical modelling, shows that a more efficient approach is needed for the Western part of Romania. The economic policy must stimulate the social and economic activities, in each county. 
Also, regarding the study we can deduce that the entrepreneurs' approaches in carrying out effective activities should be based on the importance of social and entrepreneurial activities, that is on the market's demand and the extension of activities in the branches of lesser importance, meaning that these activities do not bring immediate and consistent profit.

To illustrate the evolution of activities' efficiency of SMEs in the Western area, to make predictions regarding the evolution of their economic efficiency in the future, by comparing activities with similar efficiency, we will use other approaches of multivariate analysis methods, in our future surveys.

\section{References}

1. Anderberg, M. R. (1973) Cluster Analysis for Applications, New York: Academic Press.

2. Armeanu, S.D., Vintila, G., Moscalu, M., Filipescu M.O., \& Lazar, P. (2015) Utilizarea tehnicilor de analiza cantitativa a datelor pentru estimarea riscului de faliment al Corporatiilor. Revista Economie Teoretica si Aplicata, Vol XIX, Nr. 1 (566), 86-102.

3. Anyadike-Danes, M., Bjuggren, C. M., Gottschalk, S., Hölzl, W., Johansson, D., Maliranta, M., \& Myrann, A. (2015). An international cohort comparison of size effects on job growth, Small Business Economics, Volume 44, Issue 4, 821-844.

4. Barta, P., \& Modreanu, I. (2013). Raportul Fundatiei Post-Privatizare privind sectorul IMM din Romania.

5. Babucea, A.G. (2003). Algoritmi de clasificare utilizand analiza de cluster, Lucrarile sesiunii internationale "Integrare europeana in contextual globalizarii", (pp. 409-418),

Pitesti, Ed. Agir.

6. Bianchi, M., Orto, M., Frattini, F., \& Vercesi, P. (2010). Enabling open innovation in small and medium-sized enterprises: how to find alternative applications for your technologies. $R \& D$ Management, 40(4).

7. Blei, D.M. (2008) Hierarchical clustering, Princeton University, 2-83.

8. Porras, B, G (coord) (2014) European Union, Regional Innovation Scoreboard, printed in Belgium, 14-21.

9. Bostan, I. (2014) Legislative Study on the Government regulation on some economic recovery measures, Journal of Public Administration, Finance and Law, Issue 6.

10. Brad, B., Mocan, B., Brad, E., \& Fulea, M. (2014) Leading Innovation to Improve Complex Process Performances by Systematic Problem Analysis with TRIZ. In: EPFL Lausanne, TRIZ Future Conference 14, Global Innovation Convention. Lausanne, Switzerland

11. Ciucan-Rusu, L., \& Szabo, Z. (2013) The Pyramid of Entrepreneurship in Romania: Towards New Approach. In: B. Ramadani and C. Schneider, eds., Entrepreneurship in the Balkans. Springer-Verlag.

12. Danacica, D.E. (2006) Cluster Analysis in the Study of Life Quality on the Central and Eastern European Countries, Zagreb International Review of Economics and Business, ZIREB, Vol.X,Nr.1, Croatia, 45-61. 
Gaga L., Gabor A., Naaji A., Popescu M.P. (2016)

Analysis of the evolution of SMEs in Western Romania between 2011-2014, using the mathematical modeling

13. Gordon, Ian R., \& McCann Ph. (2005). Clusters, Innovation, Agglomeration and Regional Development, Journal of Economic Geography 5, 523-543. Retrieved from: https://www.researchgate.net/publication/5213342_Innovation_Agglomeration_and_Regio nal_Development

14. Gunasekaran, A., \& Ngai, E.W.T. (2007). Knowledge management in 21st century manufacturing. International Journal of Production Research, Volume 45, Issue 11, 23912418.

15. Heck, A, Szegedi, Z, \& Storkel, M (2012) Role of Regional Cluster Development Case Study, in SMEs 'Management in the $21^{\text {st }}$ Century, Csestochowa, 385-397.

16. Herbei Mot, I. (2014). Empirical study regarding perceptions of the ifrs for SMEs in Arad county, Studia Universitatis Vasile Goldis Arad, Seria Stiinte Economice. 24(1), 131139.

17. Isarescu, M. (2011) Rolul intreprinderilor mici si mijlocii in asigurarea cresterii economice, BNR. Retrieved from: http://www.bnro.ro/Prezentari-si-interviuri-1332.aspx?fld_issue_year=2011

18. Katz, J., \& Green, R. (2009). Entrepreneurial Small Business, Second Edition, McGraw Hill-Irwin

19. Lukacs, E. (2005). The economic role of SMEs in world economy, especially in Europe, European Integration Studies, Vol.4 No.1, Miskolc.

20. Man, M., \& Macris, M. (2013). Relevant funding of the SMEs business development in Romania in the current European context influenced by the economic, Annals of the University of Petrosani, Economics, 14(1), 161-168.

21. Muller, P., Caliandro, C., Gagliardi, D., \& Marzocchi, C. (2015) Anual Report on European SMEs 2014/2015, Athenaeum University - International Conference, Year VIII, Nr. 2(30), 310-319.

22. Neagu, O., \& Neagu, M.I. (2016). Regional specialisation and economic concentration in Romania, Studia Universitatis ,Vasile Goldis” Arad - Economics Series, vol. 26, issue 3, 1-17.

23. Paulet, E., Parnaudeau M., \& Abdessemed, T. (2014). The SME struggle for financing: a clamp down in European banks postcrisis. Journal of Business Strategy, Vol.35, Issue.2, 36-45.

24. Popa, L. (2013) Efectele crizei asupra intreprinderilor mici si mijlocii si necesitatea dezvoltarii acestora in Romania, Strategii Manageriale, 2(20), 31-37. Retrieved from: http://www.strategiimanageriale.ro/images/images_site/articole/article_7d347fdae48d392d 13b631af1d9b6362.pdf

25. Voineagu, V., Furtuna, F., Voineagu, M., \& Stefanescu, C. (2002) Analiza factoriala a fenomenelor social-economice in profil regional, Ed. Aramis.

26. *** CNIPMMR, (2011, 2012, 2013, 2014, 2015), Carta alba a IMM-urilor din Romania

27. *** CNIPMMR (2011). Strategia Consiliului National al Intreprinderilor Private Mici si Mijlocii din Romania, 2012 - 2016. 
Gaga L., Gabor A., Naaji A., Popescu M.P. (2016)

Analysis of the evolution of SMEs in Western Romania between 2011-2014, using the mathematical modeling

28. *** CNIPMMR, Evaluarea situatiei de ansamblu a IMM-urilor in semestrele I si II din 2015 (si 2011, 2012, 2013, 2014). Retrieved from: http://cnipmmr.ro/2016/03/17/evaluareasituatiei-de-ansamblu-a-imm-urilor-in-semestrele-i-si-ii-din-2015/

29. *** CNIPMMR, Dinamica activitatii IMM-urilor in perioada octombrie 2011 - martie 2015, Retrieved from: http://cnipmmr.ro/2015/08/31/dinamica-activitatii-imm-urilor-inperioada-octombrie-2011-martie-2015/

30. *** OUG nr.6 2011, completata in 2014.

31. *** Eurostat, Your Key To European Statistics (regional yearbook) 2011-2015; Statistical Atlas 2011-2015, Retrieved from: http://ec.europa.eu/eurostat/publications 32. $* * *$ SPSS for Windows

33. *** Ministerul Economiei, Comertului, si RElatiilor cu Mediul de Afaceri, Legislatie IMM. Retrieved from: http://www.aippimm.ro/articol/imm/legislatie-imm/definitie-imm 34. *** Studiu: IMM-uri din Romania (2015). Retrieved from: http://www.keysfin.com/ /UC/MediaLibrary/Handlers/ViewDocument.ashx?imageDB=true\&tbNail=0\&imageType= image\&imageID=9803\&imageName $=\&$ cultureId $=3$ 